ISSN = 1980-993X - doi:10.4136/1980-993X
www.agro.unitau.br/ambi-agua
E-mail: ambi-agua@agro.unitau.br
Tel.: (12) 3625-4116

\title{
Sensibilidade ambiental das ilhas costeiras de Ubatuba, SP, Brasil (doi:10.4136/ambi-agua.56)
}

\author{
Carolina Rodrigues Bio Polettoㅜㅜ Getulio Teixeira Batista² \\ ${ }^{1}$ Mestre em Ciências Ambientais, Universidade de Taubaté (UNITAU) \\ E-mail: carolinabio@uol.com.br \\ ${ }^{2}$ Professor do Programa de Pós-Graduação em Ciências Ambientais da Universidade de Taubaté \\ (UNITAU) \\ E-mail: getulio@agro.unitau.br
}

\section{RESUMO}

As Cartas de Sensibilidade Ambiental para Derramamentos de Óleo (Cartas SAO) constituem um componente essencial e fonte de informação primária para o planejamento de contingência, balizamento das ações de resposta e avaliação de danos em casos de derramamento de óleo. Este trabalho tem como objetivo geral elaborar um mapa de sensibilidade ambiental a vazamentos de óleo para os ambientes insulares do município de Ubatuba, Litoral Norte do Estado de São Paulo. Os objetivos específicos visaram realizar a caracterização e o diagnóstico ambiental da região. A metodologia adotada para o presente trabalho está baseada na proposta elaborada pelo Ministério do Meio Ambiente nas Especificações e Normas Técnicas para Elaboração das Cartas de Sensibilidade Ambiental a Derramamentos de Óleo (Cartas SAO). Foi realizado o levantamento de dados secundários, um trabalho de campo realizado no verão e no inverno de 2007, foi criada uma base cartográfica georreferenciada e, por fim, feita a migração dos dados obtidos em campo para a base gerada e para o banco de dados. Como resultado, obteve-se a caracterização das 34 unidades insulares do município de Ubatuba (16 ilhas, 7 ilhotes e 11 lajes) nos seguintes aspectos: físico (clima, geologia, geomorfologia e oceanografia); ambiental (fauna e flora presentes e os ecossistemas costeiros) e socioeconômico (atividades antrópicas, usos do ambiente, estruturas e os impactos gerados), e ainda, a determinação da sensibilidade ambiental dos ecossistemas insulares presentes. Foram identificadas 11 praias, localizadas em 6 ilhas, com características geomorfológicas e topográficas distintas. As praias foram classificadas com índice de sensibilidade 4, pelo fato de estarem abrigadas das ações das ondas e correntes. A maior parte dos ambientes mapeados $(44,8 \%)$ foi classificada com índice de sensibilidade 8 , indicando o alto grau de sensibilidade das regiões insulares. Os impactos gerados por derrame de óleo em ambientes costeiros podem ser significativamente minimizados durante as ações emergenciais, quando há um conhecimento prévio dos ecossistemas que integram a área atingida e, especialmente, se o ambiente está mapeado e com suas características registradas e disponíveis em bancos de dados. O mapeamento de sensibilidade ambiental é um importante instrumento de gestão e manejo, principalmente em se tratando de áreas sensíveis e carentes de instrumentos de gestão, como os ambientes insulares da região de Ubatuba.

Palavras-chave: Índice de sensibilidade ambiental; vazamentos de óleo; ambientes insulares. 
POLETTO, C. R. B.; BATISTA, G. T. Sensibilidade ambiental das ilhas costeiras de Ubatuba, SP, Brasil. Ambi-Água, Taubaté, v. 3, n. 2, p. 106-121, 2008. (doi:10.4136/ambi-agua.56)

\section{Environmental sensitivity of the coastal islands of Ubatuba, SP, Brazil}

\section{ABSTRACT}

The Environmental Sensitivity Index Maps for Oil Spills (ESI Maps, or SAO in Portuguese) constitute an essential component and source of basic information for emergency planning, response decision support and damage evaluation in case of oil spills. This study aims at the elaboration of sensitivity maps for oil spills for the islands within the Ubatuba municipality, north coast of the State of São Paulo. The adopted methodology is based on the Technical Specifications for the production of Environmental Sensitivity Maps for oil spills (SAO maps) proposed by the Brazilian Ministry of Environment. The study involved the gathering of secondary data, followed by field work carried out in the summer and winter periods of 2007; the elaboration of the cartographic base maps and, finally, the integration of the data to a GIS (Geographic Information System). As a result it was registered and mapped the physical (geology, geomorphology, oceanography and climatology), biological (fauna, flora and coastal environments) and socioeconomic (anthropic influence, human use, artificial structures and impacts) resources of Ubatuba coastal islands. Eleven beaches have been identified, located at six islands, with distinct topographic and geomorphologic features. The beaches were classified with sensitivity index 4, because they are sheltered from actions of waves and currents. Most of the mapped environments $(44.8 \%)$ were classified with sensitivity index 8 , indicating high sensitivity of the islands. The oil spill impacts on coastal environments can be significantly minimized during the contingency actions when previous knowledge of the ecosystems that compose the islands environment is available, especially when it is integrated into GIS data basis, capable of displaying easy-to-use maps. The environmental sensitivity mapping is an important management instrument, especially when dealing with sensible and poorly studied areas such as the islands of Ubatuba.

Keywords: Environmental Sensitivity Index; Oil Spill; Coastal Islands.

\section{INTRODUÇÃO}

As ilhas costeiras são ecossistemas que se desenvolveram independente de outros, o que resultou em ambientes únicos com características específicas. Devido à sua formação e isolamento, esses ambientes apresentam grande diversidade biológica e alto grau de sensibilidade ambiental.

O trecho do litoral paulista denominado Litoral Norte compreende os municípios de São Sebastião, Ilhabela, Caraguatatuba e Ubatuba, e tem como característica uma linha de costa bastante recortada, com inúmeras baías delimitadas por esporões de serra que mergulham no mar. Essa porção do litoral possui diversas ilhas, ilhotes e lajes, entre elas a Ilhabela, maior ilha costeira do Estado de São Paulo (Lamparelli et al., 1998; Ab'Saber, 2001). Segundo IPT (2000), o Litoral Norte apresenta $18,6 \%$ de sua área representada por ilhas, ilhotas e lajes; a região de Ubatuba apresenta um total de 16 ilhas, 7 ilhotes e 8 lajes (São Paulo, 1989).

Considerando a importância ecológica desses ambientes e o acelerado e desordenado crescimento populacional e turístico da zona costeira, tornou-se necessário adotar medidas de proteção legal desses ecossistemas. Dessa forma, diversas ilhas foram tombadas e outras transformadas em Unidades de Conservação, com objetivos de proteção desses ambientes (São Paulo, 1985; São Paulo, 1994).

No entanto, com o desenvolvimento da região, cujos índices de crescimento estão entre os maiores do Brasil, multiplicam-se os riscos de modificações, interferências e impactos 
POLETTO, C. R. B.; BATISTA, G. T. Sensibilidade ambiental das ilhas costeiras de Ubatuba, SP, Brasil. Ambi-Água, Taubaté, v. 3, n. 2, p. 106-121, 2008. (doi:10.4136/ambi-agua.56)

ambientais gerados por diversas atividades humanas, especialmente a expansão urbana e conseqüente especulação imobiliária, pesca, atividades turísticas e industriais.

A presença do Porto de São Sebastião e do Terminal Petrolífero da Petrobrás (TEBAR) na região agrega novos cenários aos impactos potenciais e à poluição ambiental na área. Os municípios de São Sebastião e Ilhabela são os mais afetados por esse tipo de atividade e pelos possíveis acidentes relacionados a atividades com óleo e outros produtos nocivos. No entanto, os municípios de Caraguatatuba e Ubatuba não estão livres de tais impactos. Segundo CETESB (2008), foram registrados entre 1974 e 2006, 294 acidentes envolvendo vazamentos de óleo e derivados no litoral norte. Observando os acidentes ocorridos nos últimos anos no litoral norte (Poffo, 2000), pode-se perceber que em inúmeros casos, manchas de óleo atingiram diversas regiões dos municípios de Caraguatatuba e Ubatuba, como praias e ilhas.

Um exemplo recente, foi o acidente ocorrido com o navio norueguês "Nordic Marita", ocorrido em 3 de junho de 2003, no Terminal Marítimo da Petrobrás / São Sebastião, devido ao afrouxamento de 3 braços de descarga do píer sul, quando do descarregamento de petróleo para o terminal. O óleo derramado deslocou-se do canal de São Sebastião em direção à Caraguatatuba e Ubatuba por influência de ventos e correntes marítimas, atingindo diversas praias, costões rochosos, lagoas e ilhas da região. Entre os locais atingidos, destaca-se a Ilha Anchieta, uma Unidade de Conservação insular, com ambientes extremamente sensíveis e uma rica biodiversidade.

Os danos ambientais potenciais do petróleo aos ambientes costeiros já são bastante conhecidos, variando desde a morte direta por recobrimento e/ou intoxicação, até uma variedade de efeitos subletais, comportamentais, ou danos localizados (Milanelli, 2003). A gravidade desses danos varia enormemente, de acordo com vários aspectos inerentes ao petróleo, ao tipo de ambiente atingido e à comunidade biológica afetada no acidente (São Paulo, 2007).

Os impactos gerados por derrame de óleo em ambientes costeiros podem ser significativamente minimizados durante as ações emergenciais, quando há um conhecimento prévio dos ecossistemas que integram a área atingida e, especialmente, se o ambiente está mapeado e com suas características registradas e disponíveis em bancos de dados. Assim, os métodos mais adequados de combate, contenção, recolhimento e limpeza, podem ser previamente discutidos e definidos, visando minimizar os danos adicionais aos ambientes atingidos.

Sendo assim, as Cartas de Sensibilidade Ambiental para Derramamentos de Óleo (Cartas $\mathrm{SAO}$ ) constituem um componente essencial e fonte de informação primária para o planejamento de contingência e avaliação de danos em casos de derramamento de óleo (Brasil, 2004). Ademais, as Cartas SAO representam uma ferramenta fundamental para o balizamento das ações de resposta a vazamentos de óleo, na medida em que, ao identificar aqueles ambientes com prioridade de preservação, permitem o direcionamento dos recursos disponíveis e a mobilização mais eficiente das equipes de proteção e limpeza, auxiliando na redução das conseqüências ambientais de um vazamento de óleo.

Por outro lado, é, também, possível a utilização desse instrumento como suporte técnico a outras atividades socioeconômicas e de gestão ambiental, pois apresenta uma caracterização e um diagnóstico ambiental detalhado da região estudada.

Deve-se ressaltar, no entanto, que mesmo com a padronização metodológica estabelecida pelo Ministério do Meio Ambiente, observam-se diferenças no nível de detalhamento dos diferentes mapeamentos conduzidos na costa brasileira. Produtos usados para Licenciamento Ambiental, produzidos por empresas privadas, são em geral, realizados por empresas de consultoria e, normalmente, com prazo exíguo, o que impede a realização de trabalhos detalhados. Por outro lado, os Programas conduzidos pelo MMA, por bacia sedimentar, 
POLETTO, C. R. B.; BATISTA, G. T. Sensibilidade ambiental das ilhas costeiras de Ubatuba, SP, Brasil. Ambi-Água, Taubaté, v. 3, n. 2, p. 106-121, 2008. (doi:10.4136/ambi-agua.56)

envolvem grandes extensões de costa (vários milhares de quilômetros), resultando também em uma abordagem seletiva quanto ao nível de detalhamento, focado especialmente nas áreas mais sensíveis da costa.

Pesquisas realizadas por universidades têm contribuído para o mapeamento da sensibilidade costeira ao óleo, com uma abordagem mais detalhada em alguns aspectos não contemplados nos outros mapeamentos, mas que são importantes e relevantes para a tomada de decisão e gestão de emergência em nível local (Lima, 2007; Wieczorek, 2006; Pincinato, 2007).

Sendo assim, este trabalho tem como objetivo geral, elaborar um mapa de sensibilidade ambiental a vazamentos de óleo para os ambientes insulares do município de Ubatuba, Litoral Norte do Estado de São Paulo e, como objetivos específicos, realizar a caracterização e o diagnóstico ambiental da região; identificar a sensibilidade do litoral, e áreas prioritárias de proteção e fornecer subsídios para a tomada de decisão quanto ao estabelecimento de zonas de sacrifício.

\section{MATERIAL E MÉTODOS}

A metodologia adotada para o presente trabalho está baseada na proposta elaborada pelo Ministério do Meio Ambiente nas Especificações e Normas Técnicas para Elaboração das Cartas de Sensibilidade Ambiental a Derramamentos de Óleo (Cartas SAO), e seus Anexos (Brasil, 2004). No entanto, especificidades da área, não contempladas no referido documento, foram consideradas no presente trabalho, buscando-se produzir um material que atenda da melhor forma possível a demanda local para gestão de emergências, envolvendo vazamentos de óleo e derivados.

A primeira etapa realizada foi o levantamento de dados secundários, por meio de fontes de pesquisa e contatos locais, a fim de se conhecer previamente a área estudada e também de se obter dados relevantes ao trabalho que não seriam possíveis de se obter em campo. Essas informações foram sistematizadas, inseridas em bancos de dados e representadas nas cartas geradas. A segunda etapa foi a realização do trabalho de campo. Toda a região costeira da área de abrangência do estudo foi visitada para o levantamento das informações geomorfológicas, oceanográficas, meteorológicas, biológicas e socioeconômicas, além das informações complementares como acessibilidade e infra-estrutura. A área total mapeada foi de $11.800 \mathrm{~km}^{2}$, englobando as 31 unidades insulares existentes no município.

Todas as informações levantadas em campo foram georreferenciadas com aparelho de recepção de dados do Sistema Global de Posicionamento (GPS), usando a projeção UTM, datum SAD 69 , e fuso $23 \mathrm{~S}$. Foram tomadas também fotografias digitais que foram referenciadas geograficamente e relacionadas à ilha e ao segmento onde ocorriam. Foram registrados os pontos de início e fim de cada segmento que se apresentava homogêneo em relação às características geomorfológicas, oceanográficas, tipo de substrato e tipologia da costa, aspectos fundamentais para a definição da sensibilidade ao óleo. Pontos relevantes, relacionados aos recursos biológicos e socioeconômicos (tais como atividades, ocupações, estruturas, etc.), dentro de cada segmento foram também registrados e associados a ícones específicos padronizados nas cartas SAO.

Para cada segmento foi atribuído um índice de sensibilidade do litoral (ISL), considerando suas características geomorfológicas (estrutura, declividade, tipo de sedimento) e hidrodinamismo (grau de exposição às ondas, correntes e marés). Cada segmento recebeu uma denominação específica e seqüencial, conforme determinado nas Cartas SAO (Brasil, 2004) - sigla do Estado (SP), sigla com duas letras da área de estudo (UB), letra i minúscula indicando ambiente insular, número seqüencial com três dígitos. Exemplo: SPUBi 001. 
POLETTO, C. R. B.; BATISTA, G. T. Sensibilidade ambiental das ilhas costeiras de Ubatuba, SP, Brasil. Ambi-Água, Taubaté, v. 3, n. 2, p. 106-121, 2008. (doi:10.4136/ambi-agua.56)

O trabalho de campo foi composto por duas campanhas, uma no verão (realizada em janeiro de 2007), outra no inverno (em julho de 2007), para se contemplar as características sazonais, principalmente no que diz respeito ao ambiente praial que, por influências climáticas e oceanográficas, sofre modificações de suas características geomorfológicas. Todos os ecossistemas costeiros apresentam variações mais ou menos marcantes ao longo do ano, não só nas características geomorfológicas, mas também nas biológicas, climáticas e também no grau de impacto antrópico. Da mesma forma, as características socioeconômicas e ambientais da região sofrem influências das diferentes épocas do ano, como, por exemplo, no verão, onde há um maior número de turistas (alta temporada) e um aumento da pluviosidade local; enquanto no inverno o número de turistas é menor e chove menos.

Durante a campanha de inverno, as praias foram novamente percorridas, observando-se as características geomorfológicas e hidrodinâmicas, tais como hidrodinamismo, declividade, orientação geográfica, granulometria (com de coleta de sedimentos), perfil praial (pela análise topográfica) e largura da zona entremarés. As características biológicas e socioeconômicas foram novamente registradas.

O perfil topográfico foi realizado segundo o método proposto pela CETESB (1998), e para classificação granulométrica foi realizada análise por similaridade visual, respeitando a escala de Wentworth (1922).

Os dados obtidos em campo e de levantamentos secundários compuseram um banco de dados georreferenciados da área de estudo. Da mesma forma, o banco de imagens é composto pelas fotografias georreferenciadas obtidas em campo, descrevendo as características geomorfológicas, biológicas, socioeconômicas, condições de acessibilidade ao local, bem como o índice de sensibilidade ambiental correspondente à imagem. Essas imagens estão vinculadas às cartas de sensibilidade, facilitando a visualização de cada segmento, trecho ou ponto relevante da costa, sendo indicadas com a sigla RV (recurso visual).

Ressalta-se que as Cartas de Sensibilidade apenas representam as informações essenciais e prioritárias para a gestão das emergências. $\mathrm{O}$ banco de dados vinculado às Cartas SAO disponibiliza informações adicionais em maior detalhamento, devendo ser considerado como elemento de consulta complementar às Cartas.

A base cartográfica foi elaborada com base nos aplicativos SPRING 4.2 (INPE, 2008) e ArcView 9.2 (ESRI, 2008), utilizando-se ortofotos digitais (vôo PPMA - Programa de Preservação da Mata Atlântica, com resolução espacial de $0,98 \mathrm{~m}$, adquiridas entre 2000 e 2001) cedidas pelo Instituto Florestal (São Paulo, 2002), imagens de satélite CBERS (imagens CBERS-2, sensor CCD, bandas 2, 3 e 4, com resolução espacial de 20 metros, de 15/05/2005 e de 05/07/2006), carta náutica da região (da Ilha das Couves à Ilha do Mar Virado, $\mathrm{N}^{\circ} 1.635$, Escala 1: 39.983) (Brasil, 1981) e mapas temáticos de hidrografia, malha viária, limites municipais, zoneamento ecológico econômico, entre outros.

Os demais temas geográficos utilizados na composição da base cartográfica, como malha viária, curvas de nível, hidrografia, foram disponibilizadas pelo projeto: "Concepção desenvolvimento e implementação de um sistema de informação aplicado à elaboração a cartas SAO: litoral paulista", CTPetro/MCT/CNPq, 16/2005. As informações georreferenciadas foram transferidas para a base cartográfica, como segmentos, polígonos, pontos relevantes e recursos visuais.

As cartas SAO incluíram três tipos de informações principais: a sensibilidade dos ecossistemas insulares (ISL), recursos biológicos e socioeconômicos. As feições foram representadas por linhas ou polígonos, recebendo as cores padronizadas do Índice de Sensibilidade do Litoral (ISL), de acordo com as recomendações técnicas das cartas SAO. Os segmentos receberam denominações conforme especificado nas recomendações. Os pontos foram representados por ícones, indicando os recursos biológicos e os recursos 
POLETTO, C. R. B.; BATISTA, G. T. Sensibilidade ambiental das ilhas costeiras de Ubatuba, SP, Brasil. Ambi-Água, Taubaté, v. 3, n. 2, p. 106-121, 2008. (doi:10.4136/ambi-agua.56)

socioeconômicos, respeitando-se os critérios existentes nas Especificações e Normas Técnicas para Elaboração das Cartas SAO e seus referidos Anexos (Brasil, 2004). No entanto, ícones não contemplados nas Cartas SAO e identificados na região foram criados para melhor representar a realidade estudada.

As imagens georreferenciadas foram inseridas por uma numeração seqüencial ao longo da área de estudo no sentido Norte-Sul. Todas as convenções e representações dos temas adotados foram as especificadas pelo Ministério do Meio Ambiente (Brasil, 2004). As cartas de sensibilidade ambiental a óleo - cartas SAO, foram editadas no ArcView 9.2, usando as informações armazenadas no banco de dados e seguindo as especificações e normas técnicas do Ministério do Meio Ambiente (Brasil, 2004). Foram elaboradas cartas operacionais cobrindo toda a área de estudo em uma escala 1:10.000 e cartas táticas em escala 1:100.000.

\section{RESULTADOS E DISCUSSÃO}

\subsection{Mapeamento dos ecossistemas}

De acordo com dados e observações feitas em campo, os ecossistemas presentes nas ilhas estudadas são semelhantes aos do continente. Em relação à cobertura vegetal, a Mata Atlântica está presente em todas as ilhas e ilhotes da área de estudo. Observou-se vegetação de restinga nas ilhas do Mar Virado, Anchieta, Prumirim, Porcos e Couves. As ilhas costeiras são essencialmente rochosas, sendo o ecossistema de costão rochoso predominante em todas elas.

As praias arenosas somam 11 (onze) distribuídas em 5 ilhas, a saber: Maranduba, Ilha Anchieta, Prumirim, Porcos, e Couves. Na Ilha Anchieta estão localizadas 6 praias. Esses resultados confirmam o descrito por Lamparelli et al. (1998) e São Paulo (1989). Somente na ilha Anchieta pôde ser observado o ecossistema manguezal, no entanto, ele apresenta apenas um remanescente de Avicenia Schaueriana.

As 11 praias insulares foram percorridas e caracterizadas, totalizando 11 segmentos, que somam aproximadamente $3,2 \mathrm{~km}$ de extensão total. A maioria das praias estudadas localiza-se no lado interno da ilha, ou seja, voltadas para o continente. Isso pode ser explicado pelo baixo hidrodinamismo, favorecendo a deposição de sedimentos.

Os resultados das análises granulométricas indicaram diferenças espaciais (no supralitoral, mesolitoral e infralitoral) e sazonais (verão e inverno) na granulometria das praias estudadas. O mesmo ocorreu em estudo semelhante realizado na região de Caraguatatuba e São Sebastião (Pincinato, 2007). Essas diferenças podem estar associadas aos padrões hidrodinâmicos, geomorfológicos e geográficos, e interferem significativamente na diversidade biológica e no comportamento e impacto do óleo nas praias.

Para determinação do ISL foram consideradas as amostras coletadas no mesolitoral, pois é a região mais susceptível ao óleo, e considerou-se a maior sensibilidade observada no inverno ou no verão. Todas as praias analisadas foram classificadas como ISL 4, ou seja, são classificadas como praias de areia grossa ou praias de areia fina a média, abrigadas.

A Tabela 1 mostra as diferenças granulométricas em todas as praias estudadas, tanto em relação à sazonalidade (verão e inverno) como em relação às faixas de infra, meso e supra litoral. A praia dos Porcos foi a única praia que não apresentou modificação de sedimento em nenhum dos períodos ou faixas analisadas.

Além das variações granulométricas descritas acima, as praias estudadas apresentaram grandes modificações de topografia entre os meses de verão e inverno. Apenas as praias do Engenho e dos Porcos mantiveram seu perfil topográfico nas estações analisadas (Figura 1).

Os gráficos gerados a partir do perfil topográfico exemplificam as diferenças de declive nas estações de verão e inverno, conforme exemplo da Ilha do Prumirim (Figura 2). 
POLETTO, C. R. B.; BATISTA, G. T. Sensibilidade ambiental das ilhas costeiras de Ubatuba, SP, Brasil. Ambi-Água, Taubaté, v. 3, n. 2, p. 106-121, 2008. (doi:10.4136/ambi-agua.56)

A Tabela 2 mostra as diferenças entre as praias estudadas, em relação à morfodinâmica, granulometria do mesolitoral e declividade, nos meses de verão e inverno. Existe uma estreita associação entre declive, granulometria e hidrodinamismo. As praias de areia fina têm em geral declive mais suave que as praias de areia grossa, que por sua vez tendem a ser dissipativas (Gherardi et al., 2007). As praias com predominância de areia média possuem perfis com declividade moderada, variando consideravelmente de local para local, podendo ser suaves ou mesmo atingir valores acima de $10^{\circ}$. São ditas praias de caráter intermediário, podendo ter uma tendência refletiva ou dissipativa conforme sua morfodinâmica praial.

Tabela 1. Mudança granulométrica nas estações analisadas: verão e inverno, nas praias estudadas.

\begin{tabular}{l|lll|lll}
\hline \multirow{2}{*}{ PRAIA } & \multicolumn{3}{|c|}{ VERÃO } & \multicolumn{2}{c}{ INVERNO } \\
\cline { 2 - 7 } & INFRA & MESO & SUPRA & INFRA & MESO & SUPRA \\
\hline Maranduba & grossa & média & média & grossa & média & fina \\
Palmas & muito fina & fina & média & fina a muito fina & fina a muito fina & média \\
Sapateiro & média & fina & fina & grossa & média & média \\
Presídio & média & grossa & média & grossa & média & fina \\
Engenho & média & média & média & grossa & média & média \\
Leste & muito grossa & grossa & grossa & grossa & média & média \\
Sul & grossa & média & média & grossa & média & média \\
Prumirim & média & média & grossa & média & média & média \\
Porcos & média & média & média & média & grossa & grossa \\
Couves 01 & grossa & média & média & grossa & grossa & grossa \\
Couves 02 & média & grossa & média & grossa & &
\end{tabular}

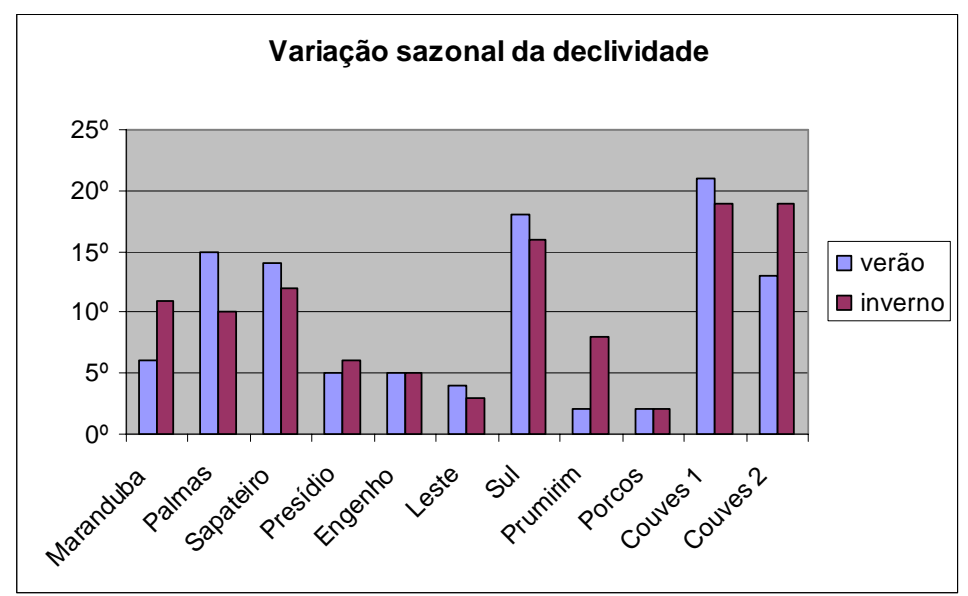

Figura 1. Variação sazonal da declividade (graus) nas praias estudadas.
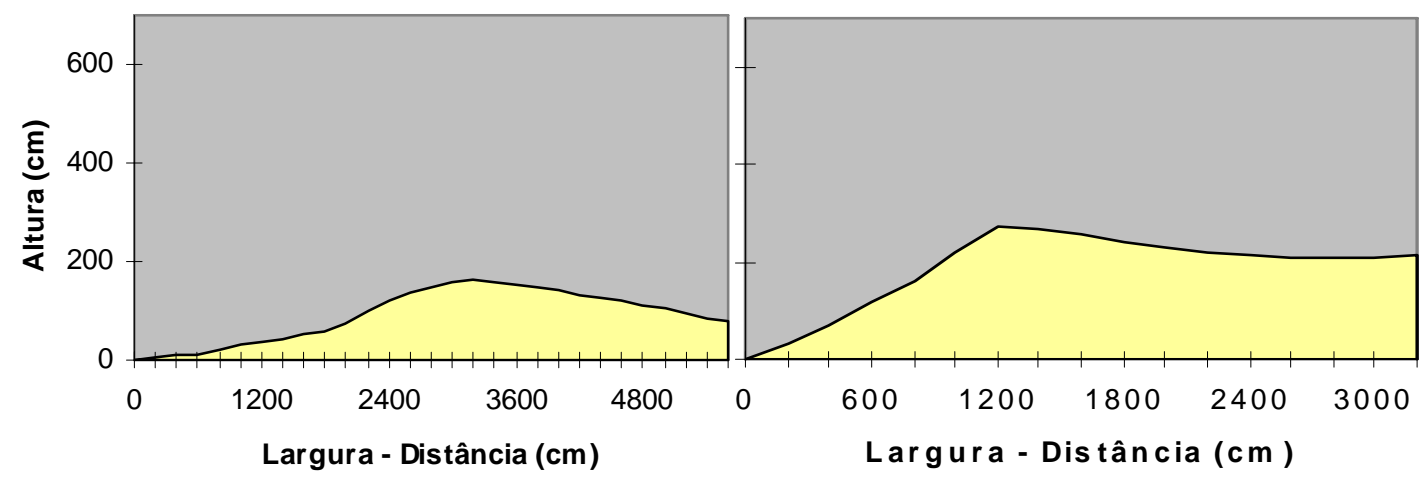

Figura 2. Perfil da Praia do Prumirim, no verão (esquerda) e no inverno (direita), na Ilha do Prumirim. 
POLETTO, C. R. B.; BATISTA, G. T. Sensibilidade ambiental das ilhas costeiras de Ubatuba, SP, Brasil. Ambi-Água, Taubaté, v. 3, n. 2, p. 106-121, 2008. (doi:10.4136/ambi-agua.56)

No entanto, se considerarmos a sazonalidade e as diferenças espaciais, os padrões granulométricos e topográficos podem sofrer grandes variações, influenciando até mesmo o ISL e determinando o comportamento do óleo. Muitos estudos de sensibilidade ambiental não consideram estas variáveis.

Tabela 2. Morfodinâmica, granulometria e declividade das praias estudadas.

\begin{tabular}{lccccc}
\hline Nome & Morfodinâmica & $\begin{array}{c}\text { Granulometria } \\
\text { verão }\end{array}$ & $\begin{array}{c}\text { Granulometria } \\
\text { inverno }\end{array}$ & $\begin{array}{c}\text { Declividade } \\
\left.\text { verão } \mathbf{(}^{\mathbf{}}\right)\end{array}$ & $\begin{array}{c}\text { Declividade } \\
\left.\text { inverno } \mathbf{(}^{\mathbf{0}}\right)\end{array}$ \\
\hline Maranduba & dissipativa & areia média & areia média & 6 & 11 \\
Palmas & dissipativa & areia fina & areia fina & 15 & 10 \\
Sapateiro & dissipativa & areia fina & areia média & 14 & 12 \\
Presídio & dissipativa & areia grossa & areia média & 5 & 6 \\
Engenho & dissipativa & areia média & areia média & 5 & 5 \\
Leste & dissipativa & areia grossa & areia média & 4 & 3 \\
Sul & reflexiva & areia média & areia média & 18 & 16 \\
Prumirim & reflexiva & areia média & areia média & 2 & 8 \\
Porcos & reflexiva & areia média & areia média & 2 & 2 \\
Couves 1 & reflexiva & areia média & areia grossa & 21 & 19 \\
Couves 2 & reflexiva & areia grossa & areia grossa & 13 & 19 \\
\hline
\end{tabular}

O período de verão é marcado por movimentos de deposição, baixo hidrodinamismo, tornando os declives das praias mais suaves, como descrito por Wieczorek (2006). Por outro lado, no inverno têm-se períodos de erosão, com alto hidrodinamismo marcado pelas ondas de tempestade e ressacas, aumentando a declividade das praias. Esse comportamento justifica a grande variação na declividade das praias de Maranduba, Prumirim e Couves 2, que tiveram um acréscimo de $6^{\circ}$ no ângulo de inclinação das praias durante o inverno. A praia do Presídio também teve um aumento de sua declividade no inverno, se comparada com o verão.

No entanto, pontos geograficamente mais abrigados propiciam a deposição de sedimentos mesmo no inverno, o que excepcionalmente diminui o declive nessa época do ano. Isso pode ser observado em canais e enseadas, como descrito por Milanelli (1994) e Wieczorek (2006) no canal de São Sebastião e Ararapira respectivamente, e evidenciado na Praia das Palmas (Ilha Anchieta), que teve sua declividade diminuída em $5^{\circ}$ no ângulo de inclinação. Além de estar localizada em uma baía abrigada, a Praia das Palmas foi classificada como sendo de areia fina, podendo ser caracterizada como uma praia deposicional em qualquer época do ano.

Essa dinâmica pode contribuir para a remoção do óleo ou o seu soterramento, dependendo do local e da época do ano. Esses resultados corroboram a necessidade de se compreender as limitações das diferentes escalas de mapeamento impostas pelas variações sazonais e espaciais dos ecossistemas. O declive e o perfil das praias são utilizados no estabelecimento de procedimentos adequados de atendimento a emergências com vazamentos de óleo e também como ações preventivas, como na classificação da vulnerabilidade da costa à poluição por óleo (São Paulo, 1998; Carmona et al., 2006). Os costões rochosos são os ecossistemas predominantes na área estudada, representando $94,9 \%$ da linha de costa mapeada, em 60,7 km de extensão não linear.

Foram mapeados e classificados 103 segmentos, com características geomorfológicas e hidrodinâmicas bastante distintas. Por se tratar de ambientes insulares, ou seja, pequenas áreas de terra circuladas por águas mais profundas do que no continente, a tendência de agitação e circulação das massas d'água é proporcionalmente maior. Por isso, da extensão total de $60,7 \mathrm{~km}$ de costão mapeados, $33,1 \mathrm{~km}(54,5 \%)$ foram classificados como de alto hidrodinamismo.

A orientação geográfica da face da rocha influi no regime de hidrodinamismo que apresenta tendências sazonais (ondulações predominantes vindas de nordeste no verão e de 
POLETTO, C. R. B.; BATISTA, G. T. Sensibilidade ambiental das ilhas costeiras de Ubatuba, SP, Brasil. Ambi-Água, Taubaté, v. 3, n. 2, p. 106-121, 2008. (doi:10.4136/ambi-agua.56)

sudeste / sudoeste no inverno) (Silva et al., 2005). Dessa forma, as faces das ilhas voltadas para mar aberto apresentaram-se com maior hidrodinamismo, pois sofrem diretamente as ações de correntes e marés. Da mesma forma, as lajes, em sua maioria em mar aberto, apresentam alto hidrodinamismo.

Costões com alto hidrodinamismo tendem a apresentar maior diversidade e riqueza de espécies, pois, devido ao efeito de espalhamento das ondas e à presença da faixa de "spray", há uma área maior para o estabelecimento das espécies nesse tipo de ambiente (Veloso et al., 1997). Da mesma forma, a declividade é um parâmetro determinante para a estruturação da comunidade biológica (Carmona et al., 2006). No campo, os segmentos de costão foram classificados visualmente apenas em três categorias qualitativas: alto declive, declive médio e declive baixo.

A tipologia foi avaliada buscando-se enquadrar os costões em categorias distintas de acordo com sua fisiografia. Os segmentos foram então classificados em costão liso (ou verdadeiro), quando se tratava de uma rocha extensa e homogênea. Rochas de grandes dimensões, isoladas ou agrupadas foram denominadas de blocos ou matacões, enquanto que pedras roladas de diversos tamanhos foram denominadas de depósito de tálus. Nos segmentos que apresentavam mais de um grupo fisiográfico, por exemplo, costão liso acompanhado de campo de matacões, todas as formações foram registradas. A tipologia classificada como costão liso foi registrada em 59 segmentos, com uma extensão total de 29,8 km representando $49 \%$ do total; matacão e depósito de tálus, 44 segmentos, com extensão total de $31 \mathrm{~km}$ e $51 \%$ do total mapeado (Tabela 3 ).

Além da proporção encontrada entre as diferentes tipologias de costão rochoso, muitos desses segmentos se mostraram bastante heterogêneos, com diversos segmentos mistos que intercalam mais de uma feição num curto espaço de tempo, aumentando ainda mais a heterogeneidade estrutural, que contribui para a riqueza biológica desses ambientes.

Tabela 3. Classificação e quantificação das tipologias encontradas.

\begin{tabular}{lccc}
\hline Morfologia & Quantidade $\left.\mathbf{( n}^{\mathbf{0}}\right)$ & Extensão $(\mathbf{k m})$ & Porcentagem (\%) \\
\hline Compacto & 59 & 29,753 & 49 \\
Matacão & 44 & 30,953 & 51 \\
\hline Total & $\mathbf{1 0 3}$ & $\mathbf{6 0 , 7 0 6}$ & $\mathbf{1 0 0}$
\end{tabular}

Quanto ao tipo de substrato, a grande maioria dos costões foi identificada como costão de granito, no entanto, costões de basalto foram identificados em diversas ilhas, tais como na Ilha do Mar Virado, Ilha Anchieta, Ilhote do Sul, Ilha das Couves e Ilha dos Porcos. Essa informação é importante por vários motivos. Primeiramente, pelo fato de a matriz rochosa afetar o grau de incrustação da biota de costões. Basaltos são menos rugosos e mais densos que os granitos, dificultando a fixação de larvas de invertebrados na zona entremarés. Além disso, o conhecimento dos costões de matriz basáltica pode contribuir para que, no futuro, equipes de campo não confundam a coloração escura desses costões, com a coloração do petróleo derramada, em vistorias a distância.

A heterogeneidade das rochas foi observada e registrada de modo geral em cada segmento de costão. A presença de fendas, tocas de ouriços, poças de maré, favorece o incremento na complexidade biótica do costão, elevando a sua biodiversidade e biomassa (Milanelli, 2003). Além disso, esses refúgios de fauna também são susceptíveis ao acúmulo de óleo, caso o costão seja atingido por uma mancha em um acidente ou vazamento. Portanto, apesar do parâmetro "refúgio", associado à heterogeneidade da rocha, não ter sido estabelecido na metodologia do MMA para as cartas SAO, esse aspecto foi considerado na presente caracterização e incorporado ao banco de dados geográfico. No entanto, esse 
POLETTO, C. R. B.; BATISTA, G. T. Sensibilidade ambiental das ilhas costeiras de Ubatuba, SP, Brasil. Ambi-Água, Taubaté, v. 3, n. 2, p. 106-121, 2008. (doi:10.4136/ambi-agua.56)

parâmetro não interferiu diretamente na categorização dos ISL dos costões rochosos, os quais levam em conta, basicamente, o hidrodinamismo, declividade e tipo fisiográfico (costão liso, tálus).

Sendo assim, com a análise dos segmentos quanto ao seu hidrodinamismo, tipologia e declividade, eles foram classificados segundo a sensibilidade. Os ISL identificados foram: ISL 1 - costões rochosos lisos, declividade alta, expostos; ISL 6 - depósito de tálus; ISL 8 encosta de rocha abrigada. A maior parte dos costões apresentou ISL 8, representando 47,3\% do total (Tabela 4).

Tabela 4. Quantificação dos costões rochosos considerando o índice de sensibilidade.

\begin{tabular}{cccc}
\hline ISL & Quantidade $\left.\mathbf{( n}^{\mathbf{0}}\right)$ & Extensão $(\mathbf{k m})$ & Porcentagem $\mathbf{( \% )}$ \\
\hline 1 & 36 & 19,6 & 32,2 \\
6 & 15 & 12,4 & 20,5 \\
8 & 52 & 28,7 & 47,3 \\
\hline Total & $\mathbf{1 0 3}$ & $\mathbf{6 0 , 7}$ & $\mathbf{1 0 0 , 0}$
\end{tabular}

No início do trabalho foram identificadas 8 lajes pelas bases oficiais e trabalhos já publicados sobre as ilhas da região. No entanto, durante o trabalho de campo foram identificadas 11 lajes de grande relevância, principalmente para navegação, pois muitas delas têm parte submersa e parte emersa, para atividades socioeconômicas como mergulho e pesca, e sob o ponto de vista biológico, abrigando grande riqueza de espécies e servindo de alimentação para muitas outras, como é o caso da tartaruga marinha. As lajes identificadas em campo foram: Laje perdida, Laje do Catimbau e Laje Itamambuca. Assim como essas lajes identificadas pela observação de campo, muitas outras não registradas devem estar presentes na região, de acordo com a maré, emergindo e submergindo.

\subsection{Sensibilidade ambiental das ilhas costeiras}

De uma maneira geral, a face das ilhas voltadas para o continente é mais abrigada que a face voltada para mar aberto. Dessa forma, esses ambientes tornam-se mais sensíveis aos acidentes de óleo.

Isso é demonstrado quando analisamos a porcentagem dos ISL classificados nos 64 quilômetros de costa mapeados. Os 122 segmentos mapeados (11 praias, 103 costões, 7 barras de rio e 1 estrutura artificial) foram classificados em ISL 1, 4, 6, 8 e 10. Os ambientes classificados com ISL 8 foram predominantes, representando $44,8 \%$ do total, conforme dados apresentados na Tabela 5.

Tabela 5. Relação entre os segmentos classificados e o Índice de Sensibilidade do Litoral.

\begin{tabular}{lccc}
\hline \multicolumn{1}{c}{ ISL } & $\begin{array}{c}\mathbf{N}^{\mathbf{0}} \mathbf{d e} \\
\text { segmentos }\end{array}$ & $\begin{array}{c}\text { Extensão total } \\
(\mathbf{k m})\end{array}$ & $\begin{array}{c}\text { Porcentagem } \\
(\mathbf{\%})\end{array}$ \\
\hline $\mathbf{1}$ - costão rochoso exposto com alta declividade & 36 & 19,6 & 30,6 \\
$\mathbf{4}$ - praias de areia grossa & 11 & 3,2 & 5,0 \\
$\quad$ - areia fina a média abrigada & 15 & 12,4 & 19,4 \\
$\mathbf{6}$ - matacão exposto & 53 & 28,7 & 44,8 \\
$\mathbf{8}$ - costão abrigado & 7 & 0,2 & 0,3 \\
$\quad$ - estrutura artificial abrigada & $\mathbf{1 2 2}$ & $\mathbf{6 4 , 0}$ & $\mathbf{1 0 0 , 0}$
\end{tabular}


POLETTO, C. R. B.; BATISTA, G. T. Sensibilidade ambiental das ilhas costeiras de Ubatuba, SP, Brasil. Ambi-Água, Taubaté, v. 3, n. 2, p. 106-121, 2008. (doi:10.4136/ambi-agua.56)

As cartas operacionais foram geradas em escala 1:10.000 (Figura 3), totalizando 19 articulações, além das duas cartas táticas em escala 1:100.000, abrangendo toda a área de estudo.
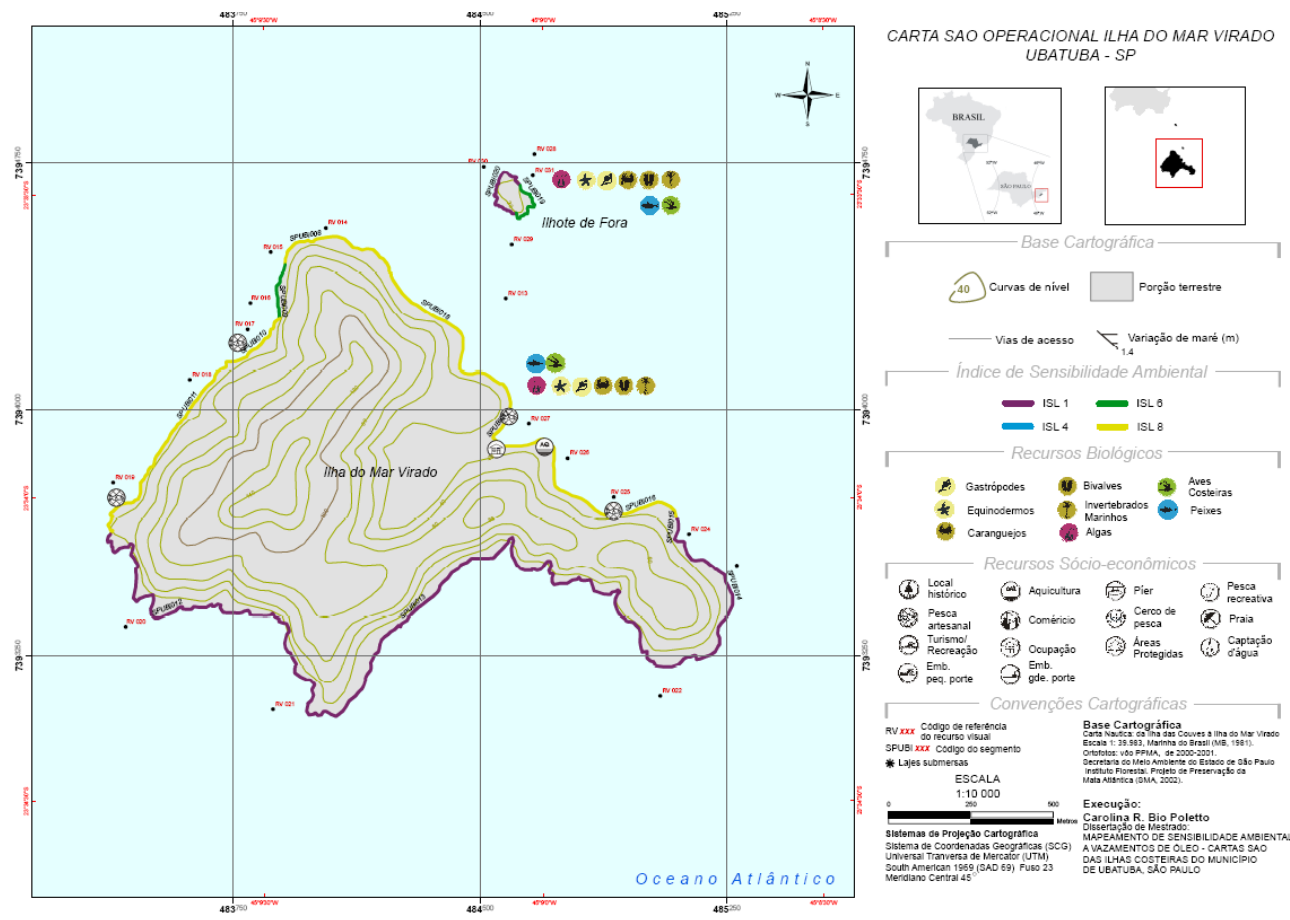

Figura 3. Exemplo de Carta Operacional gerada, da Ilha do Mar Virado, em escala (original) 1:10.000.

\subsection{Recursos biológicos}

Os recursos biológicos da área estudada foram levantados em campo por meio de observação visual e de informações obtidas com a população local, pescadores, marinheiros e moradores da região. No entanto, esse levantamento em campo não contempla a riqueza e a diversidade biológica da região. Dessa forma, a maior parte dos dados biológicos foi obtida a partir de levantamentos de dados secundários, e estão descritos no banco de dados. Para elaboração do mapa de sensibilidade, consideraram-se os recursos biológicos avistados em campo, relacionando-os com a ilha ou região em que ocorreram.

As principais espécies observadas foram: capivara (Hydrochoerus hydrochoeris); toninha (Pontoporia blainvillei); gaivotão (Larus dominicanus); atobá (Sula leucogaster); fragata (Fregata magnificiens); trinta réis (Sterna hirundinaceae); outras espécies de aves não identificadas; tartaruga verde (Chelonia Mydas); grande diversidade de peixes; fauna associada a costão rochoso, como crustáceos, moluscos, algas e equinodermos; fauna de praia, como crustáceos, moluscos e poliquetas; água viva e outros invertebrados.

No Brasil, o estudo de ilhas ainda é pouco difundido; há um número reduzido de informações sobre plantas e animais, principalmente das ilhas pequenas e/ou isoladas. No entanto, diversos estudos têm demonstrado que a estabilidade da fauna e flora insulares é muito frágil, e também, devido ao isolamento desses ecossistemas, que funciona como barreira geográfica, há uma intensificação dos mecanismos de especiação e distribuição de espécies (São Paulo, 1989; Brasil, 2002; Guillaumon, 1989; Gallo, 2006). Isso faz com que os ambientes insulares se tornem propícios ao endemismo de espécies, tornando ainda mais urgente e fundamental sua proteção.

\subsection{Aspectos socioeconômicos}


POLETTO, C. R. B.; BATISTA, G. T. Sensibilidade ambiental das ilhas costeiras de Ubatuba, SP, Brasil. Ambi-Água, Taubaté, v. 3, n. 2, p. 106-121, 2008. (doi:10.4136/ambi-agua.56)

Durante os levantamentos de campo foram observados e registrados os recursos socioeconômicos como, por exemplo, atividade antrópica, infra-estrutura, tipos de ocupação. Os seguintes usos e atividades foram encontrados nos ambientes insulares de Ubatuba: áreas de realização de esportes aquáticos; atividade turística; ocupação (casas de veranistas, casas de caiçaras, ranchos de pesca, bares); pesca artesanal; aqüicultura; estrutura de apoio náutico; e caça submarina.

\section{Turismo}

O turismo é a atividade dominante na maior parte das ilhas, no entanto, essa atividade foi identificada como fortemente sazonal, com as maiores demandas durante as temporadas de verão (dezembro a fevereiro) e inverno (julho), e também durante os finais de semana e feriados prolongados, quando a população local se multiplica de 3 a 5 vezes.

\section{Ocupação}

Foram identificadas ocupações como moradias particulares, bares e ranchos de pesca nas ilhas de Maranduba, do Mar Virado, Prumirim, Porcos, Comprida, Couves e Rapada. Outras construções de habitação ocorrem na Ilha Anchieta, onde funciona a sede do Parque Estadual da Ilha Anchieta e, portanto, possui infra-estrutura para a gestão da referida Unidade. Estruturas de apoio náutico e píeres de atracação foram observados nas Ilhas Anchieta, dos Porcos e Rapada. Não há atividades de apoio náutico, com exceção da Ilha Anchieta, que conta com garagem náutica.

Ressalta-se que, se por um lado, o apelo visual e a beleza natural são atrativos, por outro lado, a ausência de estrutura de saneamento (água e esgoto), transporte, bens e serviços, são aspectos negativos que também afetam a saúde dos ecossistemas insulares. São conhecidos os problemas da falta de sistema de saneamento sanitário nas ilhas, o que resulta na degradação do ambiente e em risco de enfermidades de veiculação hídrica na população local, como já constatado na Ilha Vitória, Búzios (Arquipélago de Ilhabela) e na Ilha Anchieta.

\section{Pesca artesanal e de subsistência}

Apesar da atividade de pesca costeira ser difusa em toda a costa de Ubatuba, muitos pescadores se concentram ao redor das ilhas. Segundo Clauzet (2006), as diferentes comunidades têm pontos de pesca bem definidos, que não se sobrepõem no continente, exceto nos arredores das ilhas, onde há uma maior pressão da pesca, fato observado na Ilha do Mar Virado, mas que tende a ocorrer nas outras áreas insulares de Ubatuba.

Os principais apetrechos e artes de pesca utilizados são as redes de arrasto para camarão e peixes de fundo. A rede de espera é outra técnica difundida no entorno de ilhas e praias isoladas de Ubatuba, como observado por Clauzet et al. (2005) para a Ponta da Almada e Ilha do Mar Virado. Outras técnicas identificadas foram pesca de vara, linhada, espinhel, jangarelho (para a pesca da lula, especialmente no entorno da Ilha Anchieta e da Ilha do Mar Virado).

Ranchos de pesca foram identificados nas Ilhas do Mar Virado, da Pedra e Anchieta. Os cercos de pesca foram observados apenas na Ilha Anchieta, Ilha do Mar Virado e na Ilha do Prumirim. No entanto, por ser uma prática sazonal e móvel, outros cercos podem existir na área que não foram observados nas semanas de campo.

A exploração de moluscos e outros invertebrados nos costões rochosos é também importante forma de subsistência para várias famílias, especialmente no continente, mas foi também observada na Ilha do Mar Virado.

\section{Aqüicultura}


POLETTO, C. R. B.; BATISTA, G. T. Sensibilidade ambiental das ilhas costeiras de Ubatuba, SP, Brasil. Ambi-Água, Taubaté, v. 3, n. 2, p. 106-121, 2008. (doi:10.4136/ambi-agua.56)

Essa atividade está em franco desenvolvimento no Litoral Paulista e em Ubatuba, em parte para completar a renda das famílias de pescadores que sofrem os efeitos da redução dos estoques de pescado (Rinaldi, 2003).

No Litoral Norte de São Paulo, existem 77 famílias de produtores de mexilhões cadastradas, produzindo em 23 praias do litoral. Há centros produtores em diversas praias e ilhas, como a Ilha do Prumirim, fazendo com que Ubatuba responda por 33 \% da produção do Estado (Fagundes et al., 2004).

Nos levantamentos de campo foram observadas atividades de mitilicultura (criação de mexilhão) na Ilha Rapada e Mar Virado, e ostreicultura (criação de ostras) na Ilha das Couves. Essa última representa uma atividade não muito difundida em Ubatuba, uma vez que o mercado está vinculado aos produtores do sul de São Paulo (Cananéia).

De qualquer forma, as ilhas são adequadas para a maricultura por estarem distantes da costa, reduzindo os efeitos da poluição, e por também apresentarem condições ambientais de circulação mais adequadas. Além disso, favorecem a segurança dos cultivos, minimizando eventos predatórios.

\section{CONCLUSÃO}

Foram identificados diversos ecossistemas nas ilhas de Ubatuba tais como, costões rochosos, praias, restinga e mata atlântica. Em todas as Ilhas de Ubatuba foram registradas 11 praias arenosas. Todas elas estão localizadas na face interna das ilhas, voltada para o continente, o que explica o baixo hidrodinamismo encontrado nesses ecossistemas. As praias são bastante diversificadas em suas características geomorfológicas e apresentaram variações espaciais e sazonais (verão e inverno) na declividade, topografia e granulometria.

Essas diferenças interferem significativamente na estrutura da comunidade biológica, no comportamento e no impacto do óleo nas praias. Esses resultados mostraram a necessidade de contemplar as variações sazonais e espaciais nos levantamentos de sensibilidade ambiental dos ecossistemas, informações essas fundamentais para a gestão e tomada de decisão em ações de emergência.

Os costões são os ecossistemas predominantes nas ilhas de Ubatuba, representando em extensão cerca de $95 \%$ dos ecossistemas presentes na área de estudo. Com características geomorfológicas e hidrodinâmicas bem distintas e variadas. A maior parte dos costões (47,3\%) foi classificada com ISL 8 (encosta de rocha abrigada), ou seja, segmentos com alta sensibilidade ambiental. Aproximadamente $20,5 \%$ dos costões mapeados foram classificados com ISL 6.

Os resultados mostraram que o ambiente insular de Ubatuba é muito rico biologicamente, caracterizado como áreas estratégicas de alimentação, repouso e nidificação de aves marinhas costeiras, oceânicas, algumas delas migratórias. O grande número de espécies de ictiofauna, comprovado pela concentração de atividade pesqueira no entorno das ilhas, ressalta a importância desse ambiente para a manutenção e equilíbrio do estoque pesqueiro no litoral norte paulista.

Diversas atividades humanas foram encontradas nas ilhas, sendo predominantes a atividade turística e a pesca artesanal. O turismo insular é uma atividade sazonal, sendo mais intenso durante as temporadas de verão (dezembro a fevereiro) e inverno (julho). As ilhas com presença de praias são as mais utilizadas por turistas, sendo a Ilha Anchieta o destino mais procurado. Eventos envolvendo vazamentos de óleo no período de alta temporada tendem a gerar graves impactos socioeconômicos na atividade.

Os resultados demonstram claramente que as ilhas de Ubatuba estão em excelentes condições de conservação e que os impactos antrópicos ainda são poucos e localizados. No 
POLETTO, C. R. B.; BATISTA, G. T. Sensibilidade ambiental das ilhas costeiras de Ubatuba, SP, Brasil. Ambi-Água, Taubaté, v. 3, n. 2, p. 106-121, 2008. (doi:10.4136/ambi-agua.56)

entanto, observa-se um aumento de impactos potenciais ligados à urbanização acelerada, à especulação imobiliária, à atividade turística descontrolada, à caça e à pesca predatória e aos vazamentos de óleo.

Historicamente, em diversos acidentes, manchas de óleo atingiram as ilhas da região. No entanto, não há estudos efetivos que determinem com segurança os impactos causados por esses acidentes nas praias e costões insulares, o que dificulta a quantificação adequada dos impactos do óleo sobre esses ambientes.

\section{REFERÊNCIAS}

AB'SABER, A. N. Litoral do Brasil. Rio de Janeiro: Metalivros, 2001. 287p.

BRASIL. Ministério da Defesa. Marinha do Brasil. Carta náutica - da Ilha das Couves à Ilha do Mar Virado, n¹.635. Brasília: Ministério da Defesa, 1981. 1 Mapa. Escala 1: 39.983 .

BRASIL. Ministério do Meio Ambiente. Avaliação e ações prioritárias para a conservação da biodiversidade das zonas costeira e marinha. Brasília: MMA/SBF, 2002.

BRASIL. Ministério do Meio Ambiente. Especificações e Normas Técnicas para elaboração de cartas de sensibilidade ambiental para derramamentos de óleo Cartas SAO. Brasília: MMA, 2004.

CARMONA, S. L.; GHERARDI, D. F. M.; TESSLER, M. G. Environment sensitivity mapping and vulnerability modeling for oil spill response along the São Paulo State coastline. Journal of Coastal Research, Royal Palm Beach, v. 39, n. SI, p. 1456-1459, 2006.

CLAUZET, M.; RAMIRES, M.; BARRELLA, W. Pesca artesanal e conhecimento local de duas populações caiçaras (Enseada do Mar Virado e Barra do Una) no litoral de São Paulo, Brasil. MULTICIÊNCIA, A Linguagem da Ciência, n. 4, p. 1-20, maio de 2005.

CLAUZET, M. Conflitos e soluções no uso de recursos marinhos do espaço de pesca artesanal na enseada do Mar Virado, Ubatuba/SP. In: ASSOCIAÇÃO NACIONAL DE PÓS-GRADUAÇÃO E PESQUISA EM AMBIENTE E SOCIEDADE ANPPAS, 3., 2006, Brasília. Anais... Brasília: ANPPAS, 2006.

ESRI. GIS and Mapping Software. ArcView - Desktpo GIS afor mapping data integratio, and analysis. Disponível em: <http://www.esri.com/software/arcgis/arcview/about/ features.html $>$. Acesso em: junho de 2008.

FAGUNDES, L.; GELLI, V.C.; OTANI, M. N.; VICENTE, M. C. M.; FREDO, C. E. Perfil sócio-econômico dos mitilicultores do litoral paulista. Informações Econômicas, São Paulo, v. 34, n. 5, maio 2004.

GALLO, B. Pesquisa e conservação das tartarugas marinhas no Parque Estadual da Ilha Anchieta. Ubatuba: Fundação Pró-Tamar, 2006.

GHERARDI, D. F. M.; CABRAL, A. P.; KLEIN, A. H. F.; MUEHE, D.; NOERNBERG, M. A.; SARTOR, S. et al. (Orgs.). Atlas de sensibilidade ambiental ao derramamento de óleo da bacia marítima de Santos. Brasília: MMA, SMCQA, 2007. v. 1. 116 p. 
POLETTO, C. R. B.; BATISTA, G. T. Sensibilidade ambiental das ilhas costeiras de Ubatuba, SP, Brasil. Ambi-Água, Taubaté, v. 3, n. 2, p. 106-121, 2008. (doi:10.4136/ambi-agua.56)

Guillaumon, J. R. et al. Plano de manejo do Parque Estadual da Ilha Anchieta. Ubatuba: Instituto Florestal, 1989. (Série Registros, 1).

INSTITUTO NACIONAL DE PESQUISAS ESPACIAIS - INPE. Sistema de Processamento de Informações Georreferenciasdas (SPRING). Disponível em: $<$ http://www.dpi.inpe.br/spring/>. Acesso em: junho de 2008.

INSTITUTO DE PESQUISAS TECNOLÓGICAS - IPT. Relatório Zero. Plano de Bacias do Litoral Norte. Brasília: IPT, 2000.

LAMPARELli C. C. et al. Mapeamento dos ecossistemas costeiros do Estado de São Paulo. São Paulo: SEMA, CETESB. 1998.

LIMA, M. V. Mapeamento de sensibilidade ambiental ao óleo do Arquipélago de Ilhabela - SP. 2007. Dissertação (Mestrado em Geociências e Meio Ambiente) Instituto de Geociências e Ciências Exatas, Universidade Estadual Paulista Júlio de Mesquita Filho, Rio Claro, 2007.

MILANELLI, J. C. C. Efeitos do petróleo e da limpeza por jateamento em um costão rochosos da praia de Barequeçaba, São Sebastião, SP. 1994. Dissertação (Mestrado em Oceanografia Biológica) - Instituto Oceanográfico, Universidade de São Paulo, São Paulo, 1994.

MILANELLI, J. C. C. Biomonitoramento de costões rochosos - instrumento para avaliação de impactos gerados por vazamentos de óleo na região do Canal de São Sebastião, SP. 2003. Tese (Doutorado em Oceanografia Biológica) - Instituto Oceanográfico, Universidade de São Paulo, São Paulo, 2003.

PINCINATO, F. L. Mapeamento da sensibilidade ambiental a derramamentos de óleo para a região costeira de São Sebastião e Caraguatatuba, litoral norte de São Paulo, SP. 2007. Dissertação (Mestrado em Geociências e Meio Ambiente) - Instituto de Geociências e Ciências Exatas, Universidade Estadual Paulista Júlio de Mesquita Filho, Rio Claro, 2007.

POFFO I. R. F. Vazamento de óleo no litoral norte do Estado de São Paulo: análise histórica (1974 a 1999). 175p. Dissertação (Mestrado em Ciências Ambientais)Programa de Ciências Ambientais (PROCAM), Universidade de São Paulo, São Paulo, 2000.

RINALDI, F. D. Produção, comercialização e perspectivas de expansão da atividade de cultivo de mexilhões Perna perna (L.) na região de Ubatuba/SP. In: SIMPÓSIO INTERNACIONAL DE INICIAÇÃO CIENTÍFICA DA UNIVERSIDADE DE SÃO PAULO, 11., 2003, Piracicaba. Anais... São Paulo: USP, 2003. 1 CD_ROM.

SÃO PAULO (Estado). Secretaria de Estado da Cultura. Conselho de Defesa do Patrimônio Histórico, Arqueológico, Artístico e Turístico do Estado. Resolução n. 40 de 06 de junho de 1985. Tombamento da Serra do Mar, de Paranapiacaba, ilhas. 1985. Disponível em: <http://www.tombamentodaserradomar.org.br/doc/DiretrizesNormas RecomendacoesPreliminares\%20.doc $>$. Acesso em: junho 2008.

SÃO PAULO (Estado). Secretaria de Estado da Cultura. Conselho de Defesa do Patrimônio Histórico, Arqueológico, Artístico e Turístico do Estado. Resolução SC-8, de 24 de março de 1994. Tombamento das ilhas do litoral paulista. 1994. Disponível em: 
POLETTO, C. R. B.; BATISTA, G. T. Sensibilidade ambiental das ilhas costeiras de Ubatuba, SP, Brasil. Ambi-Água, Taubaté, v. 3, n. 2, p. 106-121, 2008. (doi:10.4136/ambi-agua.56)

$<$ http://www.tombamentodaserradomar.org.br/doc/DiretrizesNormas

RecomendacoesPreliminares\%20.doc>. Acesso em: junho 2008.

SÃO PAULO (Estado). Secretaria de Estado do Meio Ambiente. Companhia de Tecnologia de Saneamento Ambiental - CETESB. Principais acidentes em São Paulo estatísticas. Disponível em: <www.cetesb.sp.gov.br/emergencia/acidente /vazamento/estatísticas>. Acesso em: 20 jan. 2008.

SÃO PAULO (Estado). Secretaria de Estado do Meio Ambiente. Companhia de Tecnologia de Saneamento Ambiental - CETESB. Determinação do declive, perfil e área entremarés de praias de areia. Procedimento Operacional Padronizado P.O.P. N ${ }^{\circ}$. DAHCMA-042. São Paulo: SEMA, 1998.

SÃO PAULO (Estado). Secretaria de Estado do Meio Ambiente. Companhia de Tecnologia de Saneamento Ambiental - CETESB. Ambientes costeiros contaminados por óleo, procedimentos de limpeza. São Paulo: SEMA, 2007.120p.

SÃO PAULO (Estado). Secretaria de Estado do Meio Ambiente. Ilhas do Litoral Paulista. São Paulo: SEMA, 1989.

SÃO PAULO (Estado). Secretaria de Estado do Meio Ambiente. Instituto Florestal. Ortofotos digitais. Programa de preservação da mata Atlântica - PPMA - SMAIF/KFW. São Paulo: SEMA, 2002.

SILVA, L. S.; MIRANDA, L. B.; CASTRO FILHO, B. M. Numerical study of circulation and thermohaline structure in the São Sebastião Channel. Revista Brasileira de Geofísica, v. 23, p. 407-425, 2005.

VELOSO, V. G.; CARDOSO, R. S.; FONSECA, D. B. Spatiotemporal characterization of the intertidal macrofauna community at Prainha Beach (Recreio dos Bandeirantes), State of Rio de Janeiro. Oecologia Brasiliensis, v. 3, p. 213-225, 1997.

WENTWORTH, W. C. Grade and class terms for clastic sediments. Journal Geology, v. 30, p. 377-392, 1922.

WIECZOREK, A. Mapeamento de sensibilidade a derramamentos de petróleo do Parque estadual da Ilha do Cardoso - PEIC e áreas do entorno. 2006. Dissertação (Mestrado em Geociências e Meio Ambiente) - Instituto de Geociências e Ciências Exatas, Universidade Estadual Paulista Júlio de Mesquita Filho, Rio Claro, 2006. 